\title{
PENDUGAAN BIOMASSA DAN SERAPAN KARBON DI BEBERAPA AREAL TAMAN HUTAN KOTA JAKARTA, BEKASI DAN BOGOR (Estimated Value of Biomass and Carbon Sequestration in Several Forest Park of Jakarta, Bekasi and Bogor)
}

\author{
Nyoto Santoso ${ }^{1}$, Sutopo $^{1 *}$, Gilang Prastya Pambudi², Vregat Febriansyah Danarta ${ }^{3}$, \\ Rohma Alif Wibisono ${ }^{3}$, Tri Puji Astuti ${ }^{3}$ dan/and Dimas Aryo Wicaksono ${ }^{3}$ \\ ${ }^{1}$ Departemen Konservasi Sumberdaya Hutan dan Ekowisata, Fakultas Kehutanan IPB, \\ Jawa Barat, Indonesia \\ Jl. Lingkar Akademik Kampus IPB Dramaga Bogor 16680; Telp: 0251-8626806; \\ Fax .: 0251-8626886. \\ E-mail: dkshe@apps.ipb.ac.id \\ ${ }^{2}$ Pusat Kajian Biodiversitas dan Rehabilitasi Hutan Tropika Fakultas Kehutanan IPB, \\ Jawa Barat, Indonesia \\ Jl. Lingkar Akademik Kampus IPB Dramaga Bogor 16680; Telp: 0251-8621677; \\ Fax.: 0251-8621256 \\ ${ }^{3}$ Corporate Environment Social Responsibilty Security General Affair and Communication, \\ PT United Tractos Tbk. Jl. Raya Bekasi Km 22, Cakung, Jakarta Timur 13910, \\ Telp.: (021) 24579999 \\ *Email: sutopo80@apps.ipb.ac.id
}

Tanggal diterima: 9 Oktober 2020; Tanggal disetujui: 9 Februari 2021; Tanggal direvisi: 3 Maret 2021

\begin{abstract}
The presence of forest park as green open space in densely populated urban areas and high traffic activities such as Jakarta, Bekasi and Bogor is important in absorbing $\mathrm{CO}_{2}$. However, the function of urban forests is limited because the studies were carried out on a small scale and at separate loci. This study aimed to estimate the biomass, storage and sequestration of carbon in five green open spaces located in Jakarta and Bogor areas. Biomass was estimated by non-destructive sampling for above ground biomass. The results estimated the forest park in Kanal Banjir Timur (KBT) absorbed $\mathrm{CO}_{2}$ of 1,000.01 ton/ha/year, the forest park at head office absorbed $\mathrm{CO}_{2}$ of 937.53 ton/ha/year, Mangrove Forest Park of Muara Tawar Bekasi absorbed $\mathrm{CO}_{2}$ of 46.10 ton/ha/year, and the Bukit Golf Pantai Indah Kapuk area absorbed $\mathrm{CO}_{2}$ of 147.91 tonnes/ha/year. Meanwhile the campus Forest Park of IPB University absorbed $\mathrm{CO}_{2}$ of 0.16 ton/ha. The value difference is influenced by parameters such as size or scale of sampling areas, number of stands, diameter, height, and coefficient value for each plant species. This study is expected to contribute in providing information and data on biomass, carbon content, and absorption in urban areas.
\end{abstract}

Keywords: Biomass, carbon sequestration, urban forest

\begin{abstract}
ABSTRAK
Keberadaan taman hutan sebagai ruang terbuka hijau di wilayah perkotaan yang padat penduduk dan aktivitas lalu lintas yang tinggi, seperti DKI Jakarta, Bekasi dan Bogor menjadi penting dalam menyerap $\mathrm{CO}_{2}$. Namun informasi dan data mengenai peran hutan kota masih sangat sedikit, karena umumnya kajian dilakukan dalam skala kecil dan pada
\end{abstract}


lokus yang terpisah-pisah. Tujuan dari penelitian ini adalah untuk menduga biomassa, simpanan dan serapan karbon pada lima ruang terbuka hijau di lima titik wilayah Jakarta dan Bogor. Metode yang digunakan untuk menduga biomasa adalah dengan non-destructive sampling untuk biomassa di atas permukaan tanah (above ground biomass). Hasil perhitungan menunjukkan bahwa ruang terbuka hijau di Taman Kanal Banjir Timur (KBT) mampu menyerap $\mathrm{CO}_{2}$ sebesar 1.000,01 ton/tahun; Taman Hutan Tractors Head Office mampu menyerap $\mathrm{CO}_{2}$ sebesar 937,53 ton/tahun, Taman Wisata Mangrove Muara Tawar Bekasi mampu menyerap karbon $\mathrm{CO}_{2}$ sebesar 46,10 ton/tahun, dan Taman Hutan Bukit Golf Pantai Indah Kapuk mampu menyerap $\mathrm{CO}_{2}$ sebesar 147,91 ton/tahun. Sementara Taman Hutan Kampus IPB Dramaga Bogor mampu menyerap $\mathrm{CO}_{2}$ sebesar 0,16 ton/tahun. Perbedaan nilai tersebut dipengaruhi oleh berbagai parameter seperti luas areal kajian, jumlah tegakan, diameter, tinggi, dan nilai koefisien pada masing-masing jenis tumbuhan. Hasil penelitian ini diharapkan dapat berkontribusi dalam memberikan informasi dan data mengenai biomassa, kandungan dan serapan karbon di wilayah kajian.

\section{Kata kunci : Biomassa, hutan kota, serapan karbon}

\section{PENDAHULUAN}

Persoalan utama yang dirasakan namun seringkali diacuhkan oleh masyarakat yang tinggal di wilayah kota besar adalah terjadinya penurunan kualitas udara sebagai akibat dari bertambahnya emisi dari gas buang. Salah satu gas buang adalah $\mathrm{CO}_{2}$ yang dapat bersumber dari kendaraan bermotor dan industri (Ismiyati, Marlita, \& Saidah, 2014; Darmanto, \& Sofyan, 2012). Kecenderungan penurunan kualitas udara terjadi selain karena kedua sumber pencemar tersebut, juga disebabkan karena sumber serapan alami, seperti pepohonan yang berfungsi menyerap gas buang $\left(\mathrm{CO}_{2}\right)$ di wilayah perkotaan sangat sedikit, bahkan pada beberapa pusat perkotaan tidak memiliki tegakan dan hanya berupa bangunan. Pentingnya tegakan pohon atau jalur hijau di wilayah perkotaan dalam menyerap gas buang tersebut karena jalur hijau di wilayah perkotaan benar-benar sangat efektif dalam mengurangi polutan gas CO (Izzah, Nasrullah, \& Sulistyantara, 2019).

Karbon dioksida $\left(\mathrm{CO}_{2}\right)$ memiliki peranan penting dalam peningkatan gas rumah kaca. Rosot karbon dioksida berhubungan erat dengan biomassa tegakan. Pohon melalui proses fotosintesis menyerap $\mathrm{CO}_{2}$ dan mengubahnya menjadi karbon organik (karbohidrat) dan menyimpannya dalam biomassa tubuh pohon (Karim,
Purwiyanto, \& Agustriani, 2019). Biomassa tumbuhan berperan penting dalam siklus karbon. Pengukuran biomassa hutan mencakup seluruh biomassa hidup yang ada di atas permukaan tanah dan di bawah permukaan tanah serta bahan organik yang mati meliputi kayu mati dan serasah.

Kota merupakan sebuah sistem terbuka, baik secara fisik maupun ekonomi, bersifat tidak statis, dan dinamis atau bersifat sementara. Keberadaan sebuah kota bertujuan dalam hal pemenuhan kebutuhan penduduk, sehingga bisa bertahan dan melanjutkan hidupnya. Seiring dengan itu, maka akan terjadi perkembangan kota sebagai pusat perdagangan, jasa permukiman, pemerintahan, budaya, pendidikan, dan rekreasi. Meningkatnya jumlah penduduk di perkotaan akan menyebabkan semakin banyaknya pemanfatan sumber daya alam dan lingkungan. Semakin banyaknya jumlah kendaraan bermotor dan berbagai industri yang menggunakan bahan bakar menyebabkan konsentrasi gas $\mathrm{CO}_{2}$ di udara semakin meningkat (Darmanto \& Sofyan, 2012). Sejalan dengan hal tersebut kualitas udara di perkotaan akan semakin buruk karena adanya pencemaran udara dari berbagai sumber yang dapat menyebabkan terjadinya pemanasan global.

Keberadaan ruang terbuka hijau di kawasan perkotaan dapat menjadi alternatif 
pengganti hutan alami yang telah terdegradasi. Kota juga merupakan pusat kegiatan yang dapat menghasilkan emisi karbon, sehingga keberadaan kawasan hijau di perkotaan perlu ditingkatkan. Fungsi vegetasi dalam ruang terbuka hijau yaitu sebagai penghasil oksigen dan penyerap karbon dioksida melalui proses fotosintesis (Hamdaningsih, Fandeli, \& Baiquni, 2010). Tumbuhan memerlukan karbon dioksida, air, dan unsur hara serta sinar matahari untuk kelangsungan hidupnya. Tumbuhan mengubah karbon dioksida dan air dengan bantuan sinar matahari (sebagai sumber energi) menjadi karbohidrat, oksigen, dan air (Yustiningsih, 2019). Karbohidrat tersebut tersimpan dalam batang, daun, bunga, ranting, dan buah, sehingga karbon yang tersimpan dalam tanaman dapat menggambarkan jumlah karbon dioksida yang terserap oleh tanaman. Tujuan dari penelitian ini adalah mengukur kandungan biomassa dan menduga nilai serapan karbon yang terserap di lima lokasi hutan kota, sehingga dapat bermanfaat dalam memberikan informasi dan data mengenai potensi biomassa dan serapan karbon di beberapa titik wilayah Jakarta, Bekasi, dan Bogor.

\section{METODOLOGI}

\section{A. Waktu dan Lokasi Penelitian}

Penelitian ini dilakukan di bulan September 2019 dan bulan Juli 2020. Pengambilan data bertempat di lima lokasi, yaitu: (1) Taman Hutan Kanal Banjir Timur (KBT) Jakarta Timur, (2) Taman Hutan United Tractors Head Office Cakung Jakarta Timur, (3) Taman Wisata Mangrove Muara Tawar Bekasi, (4) Taman Hutan Mangrove Bukit Golf Pantai Indah Kapuk Jakarta Utara, dan (5) Taman Hutan Kampus IPB Dramaga Bogor.

Taman Hutan Banjir Kanal Timur berada pada koordinat $6^{\circ} 13^{\prime} 42,16$ "LS dan $106^{\circ} 55^{\prime} 3,86^{\prime \prime} \mathrm{BT}$ dengan luas total 3,94 ha. Taman Hutan United Tractors Head Office berada pada koordinat $6^{\circ} 11^{\prime} 1,84 " L S$ dan $106^{\circ} 55^{\prime} 49,01$ "BT dengan luas total (areal taman dan gedung-gedung perkantoran) sebesar 18,8 ha. Areal taman wisata mangrove di Muara Tawar berada pada koordinat $6^{\circ} 04^{\prime} 48.3^{\prime \prime} \mathrm{LS}$ dan $107^{\circ} 00^{\prime} 10.3^{\prime \prime}$ BT, dengan luas wilayah yang tertanam mangrove adalah 0,2 ha. Areal penanaman yang berada di Taman Hutan Bukit Golf Pantai Indah Kapuk, Jakarta Utara pada koordinat $6^{\circ} 07^{\prime} 10.6^{\prime \prime} L S$ dan $106^{\circ} 44^{\prime} 24.9^{\prime \prime}$ $\mathrm{BT}$, dengan luas areal yang tertanam mangrove, yaitu 0,18 ha. Lokasi pendugaan kandungan biomassa dan serapan karbon di Taman Hutan Kampus IPB berada pada koordinat $6^{0} 32$ ' 44 " LS dan $106^{\circ} 43$ '5" BT dengan luas areal yang tertanam adalah 0,09 ha. Pengambilan data lapang dilakukan pada bulan Juni-Juli 2020. Berikut adalah gambaran peta lokasi kajian pendugaan biomassa dan serapan karbon di ketiga wilayah studi (Gambar 1).

\section{B. Metode}

Pengumpulan data untuk parameter diameter dan tinggi tanaman/pohon menggunakan metode sensus dan sampling dengan melakukan pengukuran tanpa melakukan penebangan. Metode sensus dilakukan pada lokasi Taman Kanal Banjir Timur (KBT), Taman United Tractors Head Office dan Taman Hutan Kampus IPB Dramaga Bogor. Hal ini karena kerapatan tanaman pada areal kajian tergolong tidak merata (spot tertentu) dan terdapat emplasemen (tempat terbuka) diantara tanaman. Metode sampling dilakukan di lokasi Muara Tawar Bekasi dan Bukit Golf Pantai Indah Kapuk. Hal ini karena kerapatan tanaman pada areal kajian tergolong merata.

Data yang diperoleh dengan sampling menggunakan petak contoh berbentuk bujur sangkar dengan sub plot ukuran $2 \mathrm{~m} \times 2 \mathrm{~m}$ untuk semai (pemudaan tingkat tanaman sampai setinggi $1,5 \mathrm{~m}$ ), sub plot $5 \mathrm{~m} \times 5 \mathrm{~m}$ untuk pancang (pemudaan dengan tinggi $>$ $1,5 \mathrm{~m}$ dan diameter $<10 \mathrm{~cm}$ ), dan sub plot $10 \mathrm{~m} \times 10 \mathrm{~m}$ untuk pohon (diameter $10 \mathrm{~cm}$ ) (Warpur, 2016). Petak contoh tersebut 
diletakkan pada wilayah penanaman berupa mangrove karena kondisi tegakan cenderung mengelompok. Pada setiap plot diidentifikasi jenis tumbuhan di ekosistem mangrove yang ditemukan secara menyeluruh dengan berpedoman pada buku Panduan Pengenalan Mangrove Indonesia (Noor, Khazali, \& Suryadiputra, 2006), mengukur lingkaran tiap batang mangrove yang ditemukan, kemudian mencatat jumlah individu masing-masing spesies mangrove tersebut.

\section{Analisis Data}

\section{Analisis potensi biomassa}

Metode yang digunakan dalam kajian ini adalah non-destructive sampling atau tanpa penebangan. Metode ini dilakukan dengan mengukur diameter pohon dengan menggunakan rumus allometrik yang sesuai untuk mengestimasi biomassa menggunakan persamaan yang dikembangkan oleh Chave, et al., (2005). Rumus allometrik dipakai untuk menaksir biomasa pohon di daerah tropis, baik ukuran besar maupun kecil, serta untuk pohon-pohon yang tumbuh di zona iklim lembab.

Rumus allometrik tersebut yaitu :

(AGB)est $=\rho \times \exp (-1,499+2,148 \ln (\mathrm{D})$

$\left.+0,207(\ln (\mathrm{D}))^{2}-0,0281(\ln (\mathrm{D}))^{3}\right)$

Keterangan:

$$
\begin{array}{ll}
\text { (AGB)est } & =\text { Above Ground Biomass } \\
\rho & =\text { Berat jenis kayu }\left(\mathrm{gram} / \mathrm{cm}^{3}\right) \\
D & =\text { Diameter }(\mathrm{cm})
\end{array}
$$

Rumus allometrik yang digunakan untuk jenis Bakau (Rhizophora sp.) menggunakan rumus allometrik Dharmawan (2010) dengan nilai $\mathrm{R}^{2}$ sebesar 0,936 yaitu:

$\mathrm{Y}=0,1466(\mathrm{Dbh})^{2,3136}$

Keterangan:
$\mathrm{Y}=$ Above Ground Biomass

Dbh $=$ Diameter setinggi dada $(\mathrm{cm})$

Selanjutnya untuk penentuan biomassa pohon persatuan luas dengan rumus:

Biomassa pohon persatuan luas $=\frac{\sum \mathbf{B}}{\mathbf{L}}$

Keterangan:

$\sum \mathrm{B}=$ Total biomassa pohon tiap kelas

$\mathrm{L}=$ Luas areal (ha)

\section{Analisis potensi karbon}

Kandungan karbon dari biomassa pohon yang diperoleh dihitung dengan cara dikalikan 0,5 (ton/ha) menurut Brown (1997).

\section{Serapan karbon dioksida $\left(\mathrm{CO}_{2}\right)$}

Besar simpanan karbon yang didapatkan kemudian dikonversi menjadi nilai serapan karbon dioksida $\left(\mathrm{CO}_{2}\right)$ menggunakan rumus rasio berat molekul karbon dioksida terhadap karbon sebagai berikut (Azzahra, Suryanti, \& Febrianto, 2020):

$\mathrm{CO}_{2}=\frac{44}{12} \mathrm{C}$

Keterangan:

$$
\begin{array}{rlll}
\left(\mathrm{CO}_{2}\right)= & \text { Jumlah gas }\left(\mathrm{CO}_{2}\right) & \text { yang } \\
& \text { diserap (ton/ha) } & \\
\mathrm{C}= & \text { Jumlah karbon } \\
& \text { disimpan (ton/ha) } &
\end{array}
$$

Hasil analisis data kandungan biomassa dan serapan karbon merupakan ekspresi pendugaan hanya untuk 1 tahun, yaitu pada tahun dilakukan pengambilan data (lokasi 1 dan 2) pada tahun 2019 dan lokasi 3, 4, dan 5 pada tahun 2020, sehingga tidak berlaku atau dapat dikonversi pada tahun sebelum dan pada tahun berikutnya. 
Nyoto Santoso, Sutopo, Gilang Prastya Pambudi, Vregat Febriansyah Danarta, Rohma Alif Wibisono, Tri Puji Astuti dan/and Dimas Aryo Wicaksono
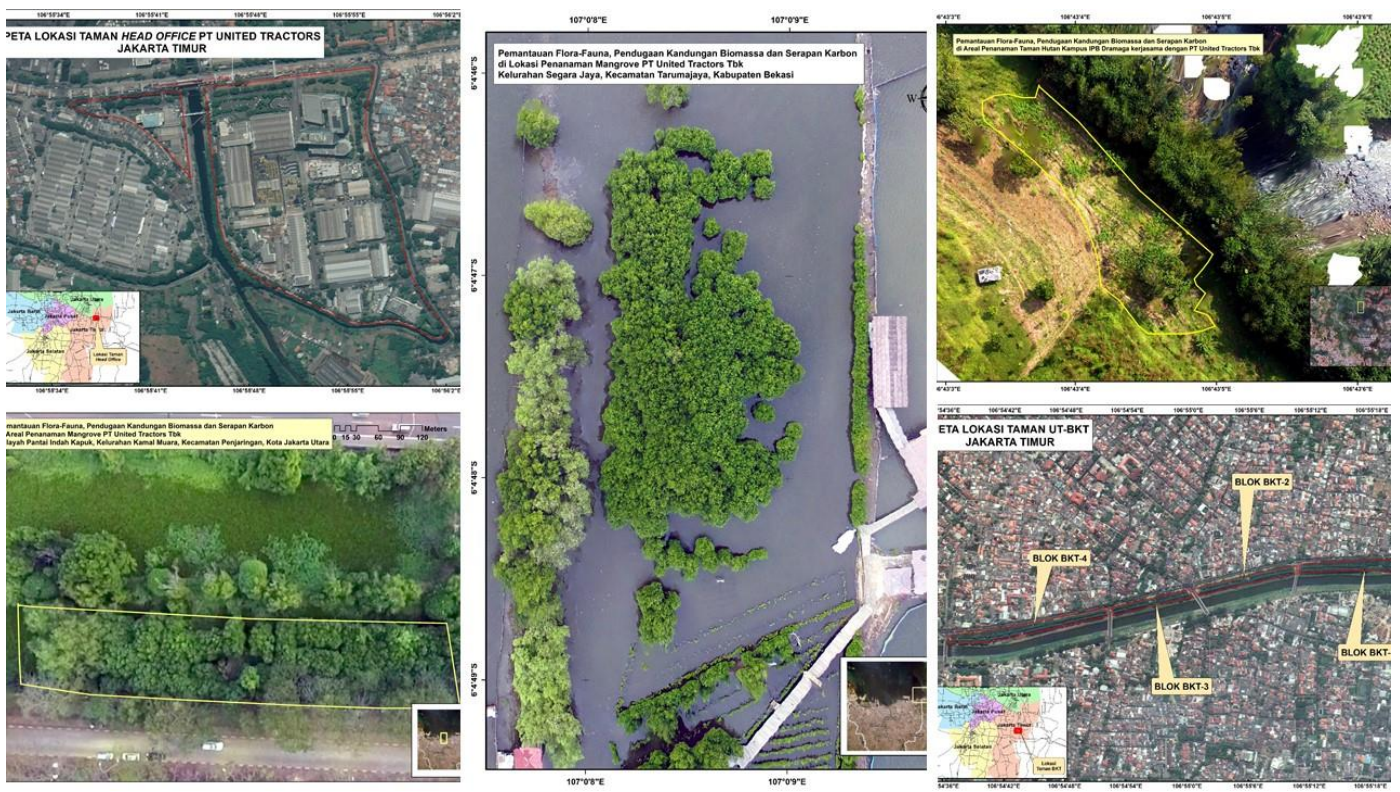

Gambar (Figure) 1. Peta lokasi pengambilan data biomassa dan serapan karbon di wilayah DKI Jakarta, Bekasi, dan Bogor (Location map for biomass and carbon sequestration data collection in DKI Jakarta, and Bogor areas)

\section{HASIL DAN PEMBAHASAN}

\section{A. Hasil}

Rekapitulasi hasil perhitungan pendugaan biomassa dan serapan karbon dioksida $\left(\mathrm{CO}_{2}\right)$ di keseluruhan areal kajian dapat dilihat pada Tabel 1.

1. Kandungan biomassa dan nilai serapan karbon di Taman Hutan Banjir Kanal Timur (BKT)

Taman Hutan Kanal Banjir Timur (KBT) memiliki empat blok taman hutan dan pada keempat blok memliki nilai kandungan karbon berbeda. Adapun hasil rekapitulasi biomassa dan kandungan karbon di Taman Hutan KBT (blok 1-blok 4) disajikan pada Tabel 2 dan untuk penjelasan masing-masing blok disajikan pada pada Tabel 3 sampai Tabel 6 .

Blok taman hutan yang memiliki kandungan biomassa dan serapan karbon yang terbesar yaitu pada blok 1, yaitu sebesar 197,75 ton (biomassa) dan 340,79 ton $\mathrm{CO}_{2}$ (serapan karbon). Hal ini karena pada blok 1 memiliki jenis yang beragam dengan kerapatan paling tinggi dari blok lainnya. Jenis yang paling dominan pada Taman Hutan BKT ini adalah jenis Eucalyptus deglupta. Jenis ini berada pada masing-masing blok di Taman Hutan BKT dengan jumlah yang paling tinggi. Kemampuan pohon-pohon di Taman Hutan BKT dalam penyerapan karbon $\mathrm{CO}_{2}$ sebesar 1.000,01 ton/ha. Berikut adalah hasil analisis karbon yang terdapat di masingmasing blok di Taman Hutan BKT (Tabel 3 sampai Tabel 6).

Pada Tabel 3 menunjukkan bahwa jenis Eucalyptus deglupta memiliki simpanan karbon tertinggi dari jenis lainnya, yaitu sebesar 50,82 ton dengan luas blok 1,13 ha. Hal ini dikarenakan jenis tersebut memiliki diameter yang besar dan jumlah pohon yang banyak, yaitu 94 pohon.

Pada Tabel 4 menunjukkan bahwa jenis Eucalyptus deglupta memiliki simpanan karbon tertinggi dari jenis lainnya yaitu sebesar 33,12 ton dengan luas blok 0,78 ha. Hal ini dikarenakan pada jenis tersebut memiliki diameter yang besar dan jumlah yang banyak, yaitu 90 pohon. 
Tabel (Table) 1. Rekapitulasi nilai pendugaan biomassa dan serapan Karbon dioksida $\left(\mathrm{CO}_{2}\right)$ (Recapitulation of estimated value of biomass and carbon dioxide $\left(\mathrm{CO}_{2}\right)$ sequestration)

\begin{tabular}{|c|c|c|c|c|}
\hline No & Lokasi (Location) & $\begin{array}{c}\text { Luas (Area) } \\
\text { (ha) }\end{array}$ & $\begin{array}{c}\text { Biomassa } \\
\text { (Biomass) (ton) }\end{array}$ & $\mathrm{CO}_{2}$ (ton) \\
\hline 1 & Taman Hutan Kanal Banjir Timur & 3,94 & 580,277 & $1.000,014$ \\
\hline 2 & $\begin{array}{l}\text { Taman Hutan United Tractors Head Office } \\
\text { United Tractors }\end{array}$ & 18,80 & 543,973 & 937,526 \\
\hline 3 & $\begin{array}{l}\text { Taman Wisata Mangrove Muara Tawar } \\
\text { Bekasi }\end{array}$ & 0,20 & 25,166 & 46,102 \\
\hline 4 & $\begin{array}{l}\text { Taman Hutan Bukit Golf Pantai Indah } \\
\text { Kapuk }\end{array}$ & 0,18 & 80,677 & 147,907 \\
\hline 5 & Taman Hutan Kampus IPB Dramaga Bogor & 0,09 & 0,092 & 0,158 \\
\hline
\end{tabular}

Tabel (Table) 2. Total biomassa dan kandungan karbon di Taman Hutan KBT (Total biomass and carbon sequestration in KBT Forest Park)

\begin{tabular}{|c|c|c|c|c|c|}
\hline No & $\begin{array}{c}\text { Blok } \\
(\text { Block })\end{array}$ & $\begin{array}{l}\text { Luas areal } \\
(\text { Area })(\text { ha) }\end{array}$ & $\begin{array}{c}\text { Biomassa } \\
\text { (Biomass) } \\
\text { (Ton) }\end{array}$ & $\begin{array}{c}\text { Karbon (Carbon) } \\
\text { (Ton) }\end{array}$ & $\mathrm{CO}_{2}$ (Ton) \\
\hline 1. & $\begin{array}{l}\text { Blok } \\
\text { (Block) } 1\end{array}$ & 1,13 & 197,751 & 92,944 & 340,793 \\
\hline 2. & $\begin{array}{l}\text { Blok } \\
\text { (Block) } 2\end{array}$ & 0,78 & 114,002 & 53,581 & 196,463 \\
\hline 3. & $\begin{array}{l}\text { Blok } \\
\text { (Block) } 3\end{array}$ & 0,59 & 85,918 & 40,381 & 148,065 \\
\hline 4. & $\begin{array}{l}\text { Blok } \\
\text { (Block) } 4\end{array}$ & 1,44 & 182,606 & 85,825 & 314,692 \\
\hline \multicolumn{3}{|c|}{ Total } & 580,277 & 272,731 & $1.000,014$ \\
\hline
\end{tabular}

Sumber (Source): Data primer pengukuran lapang (Primary data from field observation)

Tabel (Table) 3. Total biomassa dan kandungan karbon di Taman Hutan KBT Blok 1 (Total biomass and carbon content in the KBT Forest Park Block 1)

\begin{tabular}{|c|c|c|c|c|}
\hline No. & Jenis (Type) & $\begin{array}{c}\text { Nama ilmiah } \\
\text { (Scientific name) }\end{array}$ & $\begin{array}{c}\text { Biomassa } \\
\text { (Biomass) (ton) }\end{array}$ & $\begin{array}{c}\text { Karbon (Carbon) } \\
\text { (ton) }\end{array}$ \\
\hline 1. & Bintaro & Cerbera manghas $\mathrm{L}$. & 6,675 & 3,137 \\
\hline 2. & Flamboyan & Delonix regia (Hook.) Raf & 19,257 & 9,051 \\
\hline 3. & Jambu Air & Syzigium aqueum (Burm. f.) Alston & 0,607 & 0,285 \\
\hline 4. & Unidentification & Unidentification & 0,149 & 0,070 \\
\hline 5. & Ketapang Kencana & Terminalia mantaly H Perrier & 6,470 & 3,041 \\
\hline 6. & Mahoni & Swietenia mahagoni (L.) Jacq. & 0,605 & 0,285 \\
\hline 7. & Mangga & Mangifera sp. & 0,596 & 0,280 \\
\hline 8. & Pelangi & Eucalyptus deglupta Blume. & 108,127 & 50,819 \\
\hline 9. & Tanjung & Mimusops elengi $\mathrm{L}$. & 0,410 & 0,192 \\
\hline \multirow[t]{2}{*}{10.} & Trembesi & Samanea saman (Jacq.) Merr. & 54,856 & 25,782 \\
\hline & & Total & 197,751 & 92,943 \\
\hline
\end{tabular}

Sumber (Source): Data primer pengukuran lapang (Primary data from field observation) 
Nyoto Santoso, Sutopo, Gilang Prastya Pambudi, Vregat Febriansyah Danarta, Rohma Alif Wibisono, Tri Puji Astuti dan/and Dimas Aryo Wicaksono

Tabel (Table) 4. Total biomassa dan kandungan karbon di Taman Hutan KBT Blok 2 (Total biomass and carbon content at KBT Forest Park Block 2)

\begin{tabular}{|c|c|c|c|c|}
\hline No. & Jenis (Type) & $\begin{array}{c}\text { Nama ilmiah } \\
\text { (Scientific name) }\end{array}$ & $\begin{array}{c}\text { Biomassa (Biomass) } \\
\text { (ton) }\end{array}$ & Karbon (Carbon) (ton) \\
\hline 1. & Beringin & Ficus benjamina L. & 0,041 & 0,019 \\
\hline 2. & Bintaro & Cerbera manghas L. & 0,026 & 0,012 \\
\hline 3. & Flamboyan & Delonix regia (Hook.) Raf & 29,228 & 13,737 \\
\hline 4. & Glodokan tiang & Polyalthia longifolia Sonn. & 3,657 & 1,719 \\
\hline 5. & Kayu Putih & Melaleuca leucadendra $\mathrm{L}$. & 0,016 & 0,007 \\
\hline 6. & Ketapang & Terminalia catappa $\mathrm{L}$. & 0,080 & 0,038 \\
\hline 7. & Mahoni & Swietenia mahagoni (L.) Jacq & 0,336 & 0,158 \\
\hline 8. & Mangga & Mangifera $s p$ & 1,672 & 0,786 \\
\hline 9. & Nyamplung & Calophyllum inophyllum & 0,176 & 0,083 \\
\hline 10. & Pelangi & Eucalyptus deglupta & 70,469 & 33,120 \\
\hline 11. & Tanjung & Mimusops elengi L. & 0,544 & 0,256 \\
\hline \multirow[t]{2}{*}{12.} & Trembesi & Samanea saman (Jacq.) Merr. & 7,756 & 3,645 \\
\hline & & Total & 114,002 & 53,581 \\
\hline
\end{tabular}

Tabel (Table) 5. Total biomassa dan kandungan karbon di Taman Hutan KBT Blok 3 (Total biomass and carbon sequestration at KBT Forest Park Block 3)

\begin{tabular}{cllrr}
\hline No. & Jenis (Type) & \multicolumn{1}{c}{$\begin{array}{c}\text { Nama ilmiah } \\
\text { (Scientific name) }\end{array}$} & $\begin{array}{c}\text { Biomassa (Biomass) } \\
\text { (ton) }\end{array}$ & $\begin{array}{c}\text { Karbon (Carbon) } \\
\text { (ton) }\end{array}$ \\
\hline 1. & Flamboyan & Delonix regia (Hook.) Raf & 22,517 & 10,583 \\
2. & Mahoni & Swietenia mahagoni (L.) Jacq & 0,672 & 0,316 \\
3. & Mindi & Melia azedarach L. & 1,363 & 0,641 \\
4. & Pelangi & Eucalyptus deglupta Blume & 37,296 & 17,529 \\
5. & Sirsak & Annona muricata Linn. & 0,258 & 0,121 \\
6. & Tanjung & Mimusops elengi L. & 2,152 & 1,011 \\
7. & Trembesi & Samanea saman (Jacq.) Merr. & 21,661 & 10,180 \\
\hline & Total & 85,918 & 40,381 \\
\hline
\end{tabular}

Sumber (Source): Data primer pengukuran lapang (Primary data from field observation)

Tabel (Table) 6. Total biomassa dan kandungan karbon di Taman Hutan KBT Blok 4 (Total biomass and carbon sequestration at KBT Forest Park Block 4)

\begin{tabular}{cllrc}
\hline No. & \multicolumn{1}{c}{ Jenis (Type) } & \multicolumn{1}{c}{$\begin{array}{c}\text { Nama ilmiah } \\
\text { (Scientific name) }\end{array}$} & $\begin{array}{c}\text { Biomassa (Biomass) } \\
\text { (ton) }\end{array}$ & $\begin{array}{c}\text { Karbon (Carbon) } \\
\text { (ton) }\end{array}$ \\
\hline 1. & Flamboyan & Delonix regia (Hook.) Raf & 12,097 & 5,685 \\
2. & Kapuk Randu & Ceiba pentandra (L.) Gaertn & 1,104 & 0,520 \\
3. & Ketapang Kencana & Terminalia mantaly H Perrier & 1,920 & 0,901 \\
4. & Mahoni & Swietenia mahagoni (L.) Jacq & 10,885 & 5,116 \\
5. & Nangka & Artocarpus heterophyllus Lamk. & 0,124 & 0,058 \\
6. & Pelangi & Eucalyptus deglupta Blume. & 98,238 & 46,172 \\
7. & Tanjung & Mimusops elengi L. & 0,501 & 0,236 \\
8. & Trembesi & Samanea saman (Jacq.) Merr. & 57,737 & 27,137 \\
\hline
\end{tabular}

Sumber (Source): Data primer pengukuran lapang (Primary data from field observation)

Pada Tabel 5 menunjukkan bahwa jenis E. deglupta memiliki simpanan karbon tertinggi dari yang lain, yaitu sebesar 17,529 ton dengan luas blok sebesar 0,59 ha. Hal tersebut karena E. deglupta memiliki diameter yang besar dan jumlah yang banyak, yaitu 52 pohon.
Berdasarkan Tabel 6 tersebut menunjukkan bahwa jenis E. deglupta tetap menjadi yang paling tertinggi dengan nilai karbon sebesar 46,172 ton. Hal ini dikarenakan pada jenis Pelangi memiliki diameter yang besar dan jumlah yang banyak yaitu 138 pohon dengan luas blok 4 , yaitu 1,44 ha. 
2. Kandungan biomassa dan nilai serapan karbon di Taman Hutan Head Office PT United Tractors Tbk

Jenis yang memiliki nilai serapan karbon tertinggi adalah jenis Pterocarpus indicus. Hal ini dikarenakan jenis tersebut memiliki diameter yang besar dan jumlahnya banyak (75 pohon), sehingga mempengaruhi nilai karbonnya. Kemampuan pohon-pohon di Taman Hutan United Tractors Head Office dalam penyerapan karbon $\mathrm{CO}_{2}$ sebesar 937,526 ton. Berikut adalah hasil rekapitulasi nilai dan serapan karbon pada vegetasi di sekitar Taman Hutan United Tractors Head Office (Tabel 7).

\section{Kandungan biomassa dan nilai} serapan karbon di Taman Hutan Mangrove Muara Tawar Bekasi

Nilai biomassa dan serapan karbon tertinggi di wilayah Taman Hutan Mangrove Muara Tawar Bekasi dimiliki oleh jenis R. mucronata, dengan nilai biomassa 24,46 ton dan nilai karbon 12,23 ton. Selain itu, jenis tersebut memiliki nilai serapan karbon (ton) tertinggi dibandingkan dengan jenis lainnya dengan luas areal kajian sebesar 0,2 ha. Hal ini dikarenakan jenis R. mucronata memiliki jumlah pohon yang paling banyak, yaitu 1.640 pohon. Kemampuan pohon-pohon tanaman $P T$ United Tractors Tbk di Taman Hutan Mangrove Muara Tawar Bekasi dalam penyerapan $\mathrm{CO}_{2}$ sebesar 46,10 ton. Berikut adalah hasil analisis karbon yang terdapat di areal Taman Hutan Mangrove Muara Tawar Bekasi (Tabel 8).

\section{Kandungan biomassa dan nilai serapan karbon di Taman Hutan Bukit Golf Pantai Indah Kapuk}

Kandungan biomassa dan nilai serapan karbon yang berada di lokasi Taman Hutan Bukit Golf Pantai Indah Kapuk memiliki perbedaan berdasarkan pada jenis tanaman yang diukur, yaitu hanya ada lima jenis yang berada di lokasi sampling. Kelima jenis tersebut diantaranya adalah bakau kurap (R. mucronata), bintaro (C. manghas), flamboyan (D. regia), trembesi (S. saman), dan lamtoro (L. leucocephala). Adapun kandungan karbon pada masingmasing jenis tanaman yang berada di lokasi sampling Taman Hutan Bukit Golf Pantai Indah Kapuk disajikan pada tabel berikut (Tabel 9).

Tabel (Table) 7. Total biomassa dan nilai serapan karbon di Taman Hutan United Tractors Head Office (Total biomass and carbon sequestration value in United Tractors Head Office Forest Park)

\begin{tabular}{|c|c|c|c|c|c|}
\hline No. & Jenis (Type) & $\begin{array}{c}\text { Nama ilmiah } \\
\text { (Scientific name) }\end{array}$ & $\begin{array}{c}\text { Biomassa } \\
(\text { Biomass }) \text { (ton) }\end{array}$ & $\begin{array}{c}\text { Karbon } \\
\text { (Carbon) (ton) }\end{array}$ & $\begin{array}{l}\mathrm{CO}_{2} \\
\text { (ton) }\end{array}$ \\
\hline 1. & Akasia & Acacia mangium Willd. & 5,245 & 2,463 & 9,043 \\
\hline 2. & Alpukat & Persea americana Mill & 0,056 & 0,038 & 0,113 \\
\hline 3. & Angsana & Pterocarpus indicus Willd & 159,424 & 74,937 & 274,762 \\
\hline 4. & Ara kijang & Ficus crassiramea Miq. & 11,656 & 5,471 & 20,078 \\
\hline 5. & Ara suci & Ficus religiosa L. & 0,752 & 0,357 & 1,297 \\
\hline 8. & Beringin & Ficus benjamina L. & 0,526 & 0,244 & 0,921 \\
\hline 9. & Biola cantik & Ficus lyrata Warb. & 6,918 & 3,252 & 11,919 \\
\hline 10. & Buah roda & Hura crepitans L. & 0,226 & 0,113 & 0,376 \\
\hline 11. & Cemara & Casuarina $s p$ & 4,550 & 2,143 & 7,858 \\
\hline 12. & Dadap merah & Erythrina crista-galli $\mathrm{L}$. & 7,934 & 3,722 & 13,668 \\
\hline 16. & Jambu biji & Psidium guajava Linn. & 0,338 & 0,169 & 0,602 \\
\hline 17. & Jambu bol & $\begin{array}{l}\text { Syzygium malaccense (L.) Merr. \& } \\
\text { L.M.Perry }\end{array}$ & 5,471 & 2,576 & 9,419 \\
\hline
\end{tabular}


Nyoto Santoso, Sutopo, Gilang Prastya Pambudi, Vregat Febriansyah Danarta, Rohma Alif Wibisono, Tri Puji Astuti dan/and Dimas Aryo Wicaksono

Lanjutan (To be continue)

\begin{tabular}{|c|c|c|c|c|c|}
\hline No. & Jenis (Type) & $\begin{array}{l}\text { Nama ilmiah } \\
\text { (Scientific name) }\end{array}$ & $\begin{array}{r}\text { Biomassa } \\
\text { (Biomass) } \\
\text { (ton) }\end{array}$ & $\begin{array}{r}\text { Karbon } \\
\text { (Carbon) } \\
\text { (ton) }\end{array}$ & $\begin{array}{l}\mathrm{CO} 2 \\
\text { (ton) }\end{array}$ \\
\hline 18. & Jambu mede & Anacardium occidentale Linn. & 0,978 & 0,451 & 1,673 \\
\hline 19. & Jati & Tectona grandis Linn. $\mathrm{f}$ & 31,791 & 14,946 & 54,783 \\
\hline 20. & Kamboja & Plumeria $s p$ & 2,745 & 1,278 & 4,719 \\
\hline 21. & Kapuk & Ceiba pentandra (L.) Gaertn & 22,353 & 10,509 & 38,540 \\
\hline 22. & Karet kebo & Ficus elastica Roxb. & 12,765 & 5,997 & 22,015 \\
\hline 23. & Kecrutan & Spathodea campanulata P.Beauv. & 1,918 & 0,902 & 3,328 \\
\hline 24. & Kersen & Muntingia calabura Linn. & 0,132 & 0,056 & 0,226 \\
\hline 25. & Ketapang & Terminalia catappa Linn. & 0,113 & 0,056 & 0,188 \\
\hline 26. & Ketapang kencana & Terminalia mantaly H Perrier & 1,034 & 0,489 & 1,786 \\
\hline 27. & Kordia & Cordia sebestena Linn. & 0,414 & 0,188 & 0,714 \\
\hline 28. & Krei payung & $\begin{array}{l}\text { Filicium decipiens (Wight \& Arn.) } \\
\text { Thwaites }\end{array}$ & 2,576 & 1,203 & 4,437 \\
\hline 29. & Lamtoro & $\begin{array}{l}\text { Leucaena leucocephala (Schltdl.) } \\
\text { Benth. }\end{array}$ & 0,733 & 0,357 & 1,278 \\
\hline 30. & Mahang damar & $\begin{array}{l}\text { Macaranga triloba (Thunb.) Mull. } \\
\text { Arg. }\end{array}$ & 0,808 & 0,376 & 1,372 \\
\hline 31. & Mahoni & Swietenia mahagoni (L.) Jacq & 0,006 & 0,003 & 0,011 \\
\hline 32. & Mangga & Mangifera indica Linn. & 103,889 & 48,824 & 179,051 \\
\hline 33. & Matoa & Pometia pinnata JR Forst. \& G. Forst. & 0,019 & 0,019 & 0,038 \\
\hline 34. & Mengkudu & Morinda citrifolia Linn. & 0,451 & 0,207 & 0,790 \\
\hline 35. & Mindi kecil & Melia azedarach Linn. & 0,226 & 0,113 & 0,395 \\
\hline 36. & Nangka & Artocarpus heterophyllus Lamk. & 6,900 & 3,234 & 11,882 \\
\hline 37. & Daun kupu-kupu & Bauhinia purpurea Linn. & 6,975 & 3,290 & 12,032 \\
\hline 38. & Pelangi & Eucalyptus deglupta Blume & 2,256 & 1,072 & 3,892 \\
\hline 39. & Sosis & Kigelia africana $($ Lam.) Benth & 10,829 & 5,095 & 18,650 \\
\hline 40. & Sawo & Manilkara zapota (L.) P. Royen & 0,338 & 0,169 & 0,583 \\
\hline 41. & Sawo kecik & Manilkara kauki Linn. & 0,902 & 0,432 & 1,560 \\
\hline 42. & Sirsak & Annona muricata Linn. & 0,008 & 0,004 & 0,015 \\
\hline 43. & Sukun & Artocarpus altilis (Park.) Fsb. & 7,088 & 3,328 & 12,201 \\
\hline 44. & Tabebuya kuning & $\begin{array}{l}\text { Handroanthus chrysotrichus (Mart. Ex } \\
\text { DC.) Mattos }\end{array}$ & 14,344 & 6,730 & 24,703 \\
\hline 45. & Tanjung & Mimusops elengi Linn. & 56,494 & 26,546 & 97,346 \\
\hline 46. & Tengguli & Cassia fistula Linn. & 2,256 & 1,053 & 3,873 \\
\hline 47. & Trembesi & Samanea saman (Jacq.) Merr. & 25,718 & 12,088 & 44,330 \\
\hline 49. & Walisongo & Schefflera actinophylla (Endl.) Harms & 0,207 & 0,094 & 0,357 \\
\hline 50. & Waru daun merah & Hibiscus tiliaceus L. & 3,741 & 1,767 & 6,448 \\
\hline & & Total & 543,973 & 255,706 & 937,526 \\
\hline
\end{tabular}

Sumber (Source): Data primer pengukuran lapang (Primary data from field observation)

Tabel (Table) 8. Total biomassa dan nilai serapan karbon di Taman Hutan Mangrove Muara Tawar Bekasi (Total Biomass and carbon sequestration at Mangrove Forest Park Muara Tawar Bekasi)

\begin{tabular}{ccccrr}
\hline No. & \multirow{2}{*}{ Jenis (Type) } & \multicolumn{1}{c}{$\begin{array}{c}\text { Nama ilmiah } \\
\text { (Scientific name) }\end{array}$} & $\begin{array}{c}\text { Biomassa (Biomass) } \\
\text { (ton) }\end{array}$ & $\begin{array}{c}\text { Karbon (Carbon) } \\
\text { (ton) }\end{array}$ & $\mathrm{CO}_{2}$ (ton) \\
\hline 1. & Bakau Kurap & Rhizophora mucronata Lam. & 24,461 & 12,231 & 44,809 \\
2. & Bakau Minyak & Rhizophora apiculata Blume & 0,272 & 0,136 & 0,498 \\
3. & Bintaro & Cerbera manghas L. & 0,433 & 0,217 & 0,794 \\
\hline \multicolumn{7}{c}{ Total } & 25,166 & 12,583 & 46,102 \\
\hline
\end{tabular}


Tabel (Table) 9. Total biomassa dan nilai serapan karbon di Taman Hutan Bukit Golf Pantai Indah Kapuk (Total biomass and carbon sequestration value at Forest Park of Bukit Golf Pantai Indah Kapuk)

\begin{tabular}{lllccc}
\hline No. & \multirow{2}{*}{ Jenis (Type) } & \multicolumn{1}{c}{$\begin{array}{c}\text { Nama ilmiah } \\
\text { (Scientific name) }\end{array}$} & $\begin{array}{c}\text { Biomassa } \\
\text { (Biomass) (ton) }\end{array}$ & $\begin{array}{c}\text { Karbon (Carbon) } \\
\text { (ton) }\end{array}$ & $\begin{array}{c}\mathrm{CO}_{2} \\
\text { (ton) }\end{array}$ \\
\hline 1. & Bakau kurap & Rhizophora mucronata Lam. & 20,610 & 10,305 & 37,785 \\
2. & Bintaro & Cerbera manghas L. & 1,534 & 0,767 & 2,812 \\
3. & Flamboyan & Delonix regia (Hook.) Raf. & 15,538 & 7,769 & 28,486 \\
4. & Trembesi & Samanea saman (Jacq.) Merr. & 35,420 & 17,710 & 64,937 \\
5. & Lamtoro & Leucaena leucocephala (Schltdl.) Benth. & 7,574 & 3,787 & 13,886 \\
\hline \multicolumn{7}{r}{} & \multicolumn{2}{c}{ Total } & 80,677 & 40,338 & 147,907 \\
\hline
\end{tabular}

Sumber (Source): Data primer pengukuran lapang (Primary data from field observation)

Tabel (Table) 10. Total biomassa dan nilai serapan karbon di Taman Hutan Kampus IPB Dramaga Bogor (Total biomass and carbon sequestration at Taman Hutan Kampus of IPB Dramaga Bogor)

\begin{tabular}{|c|c|c|c|c|c|}
\hline No. & Jenis (Type) & $\begin{array}{c}\text { Nama ilmiah } \\
\text { (Scientific name) }\end{array}$ & $\begin{array}{c}\text { Biomassa } \\
\text { (Biomass) } \\
\text { (ton) }\end{array}$ & $\begin{array}{c}\text { Karbon } \\
\text { (Carbon) } \\
(\text { ton })\end{array}$ & $\begin{array}{l}\mathrm{CO}_{2} \\
\text { (ton) }\end{array}$ \\
\hline 1. & Rasamala & Liquidambar excelsa (Noronha) Oken & 0,014 & 0,006 & 0,024 \\
\hline 2. & Meranti Tembaga & Shorea leprosula Miq. & 0,034 & 0,016 & 0,059 \\
\hline 3. & Bisbul & Diospyros discolor Willd. & 0,012 & 0,006 & 0,021 \\
\hline 4. & Eboni & Diospyros celebica Bakh. & 0,005 & 0,003 & 0,009 \\
\hline 5. & Merbau & Intsia bijuga (Colebr.) Kuntze & 0,016 & 0,007 & 0,027 \\
\hline 6. & Tengkawang Tungkul & Shorea stenoptera Burck & 0,003 & 0,001 & 0,005 \\
\hline 7. & Sanrego & Lunasia amara Blanco & 0,001 & 0,0005 & 0,002 \\
\hline 8. & Ceremai & Phyllanthus acidus (L.) Skeels & 0,001 & 0,001 & 0,002 \\
\hline 9. & Suren & Toona sureni (Blume) Merr. & 0,005 & 0,003 & 0,009 \\
\hline . & & Total & 0,092 & 0,043 & 0,158 \\
\hline
\end{tabular}

Sumber (Source): Data primer pengukuran lapang lapang (Primary data were field measurements)

Pada Tabel 9 menunjukkan bahwa jenis S. saman pada areal Taman Hutan Bukit Golf Pantai Indah Kapuk memiliki nilai biomassa (ton) dan serapan karbon (ton) tertinggi dibandingkan dengan jenis lainnya dengan luas areal kajian sebesar 0,18 ha. Hal ini dikarenakan jenis tersebut memiliki nilai rata-rata diameter pohon yang paling besar dengan jumlah individu, yaitu sebanyak 27 pohon. Kemampuan tanaman di Taman Hutan Bukit Golf Pantai Indah Kapuk dalam penyerapan $\mathrm{CO}_{2}$ sebesar 147,91 ton.

\section{Kandungan biomassa dan nilai serapan karbon di Taman Hutan Kampus IPB Dramaga Bogor}

Tanaman yang terdapat di areal Taman Hutan Kampus IPB Dramaga merupakan perwakilan dari beberapa jenis yang dilindungi dan langka dari kelompok hutan dataran. Pada Tabel 10 adalah hasil analisis karbon yang terdapat di areal Taman Hutan Kampus IPB Dramaga.

Tabel 10 menunjukkan bahwa tanaman jenis S. leprosula memiliki biomassa tertinggi dan kemampuan serapan karbon tertinggi. Hal ini dikarenakan jenis $\mathrm{S}$. leprosula memiliki diameter yang besar dengan jumlah pohon sebanyak 28 individu. Kemampuan pohon-pohon tanaman United Tractors di Taman Hutan Kampus IPB Dramaga Bogor dalam penyerapan karbon $\mathrm{CO}_{2}$ sebesar 0,16 ton.

\section{B. Pembahasan}

Pendugaan biomassa dan serapan $\mathrm{CO}_{2}$ pada kajian ini merupakan nilai riil. Faktor luas areal kajian memiliki pengaruh terhadap nilai biomassa dan serapan $\mathrm{CO}_{2}$. Hal ini dapat dilihat bahwa nilai biomassa dan serapan $\mathrm{CO}_{2}$ pada lokasi Taman Hutan KBT dan United Tractor Head Office merupakan yang terbesar karena kedua lokasi tersebut memiliki luas areal yang 
lebih luas dibandingkan lokasi kajian lainnya yang masing-masing luas arealnya di bawah 1 ha. Perbedaan nilai biomassa dan serapan $\mathrm{CO}_{2}$ di masing-masing lokasi kajian juga dipengaruhi oleh jumlah dan kerapatan pohon, diameter pohon, jenis pohon, tajuk pohon, faktor lingkungan yang meliputi penyinaran matahari, kadar air, suhu, dan kesuburan tanah yang mempengaruhi laju fotosintesis. Besarnya biomassa ditentukan oleh diameter, tinggi tanaman, kerapatan kayu, dan kesuburan tanah (Banjarnahor, Setiawan, \& Darmawan, 2018; Azizah et al., 2019; Sedjarawan, Akhbar, \& Heriyanto, 2014).

Pada lokasi Taman Hutan KBT dan United Tractor Head Office memiliki jumlah pohon yang banyak dengan rata-rata diameter yang besar, kerapatan pohon yang termasuk tinggi dan jenis pohon yang memiliki berat jenis rata-rata cukup tinggi. Diketahui bahwa pada lokasi Taman Hutan Mangrove Muara Tawar Bekasi memiliki jumlah pohon yang lebih banyak dan kerapatan yang lebih tinggi dibandingkan lokasi lainnya. Namun diameter dan tinggi pohonnya relatif lebih kecil karena tanaman/tumbuhan pada lokasi Taman Hutan Mangrove Muara Tawar Bekasi sebagian besar (99\%) masih pada tingkat pancang. Hal inipun sama dengan kondisi pohon yang berada di Taman Hutan Bukit Golf Pantai Indah Kapuk, dimana mayoritas pertumbuhan pohonnya termasuk dalam tingkat pancang. Jumlah individu yang paling sedikit dan kerapatan terendah terdapat pada lokasi Taman Hutan Kampus IPB Dramaga Bogor. Diameter dan tinggi pada tumbuhan di lokasi tersebut relatif kecil karena seluruh tumbuhannya masih pada tingkat pancang dan umur relatif masih muda ( $<1$ tahun). Hal ini mempengaruhi terhadap kandungan biomassa dan cadangan karbon karena umur mempengaruhi diameter batang tegakan, yang berbanding lurus dengan kandungan biomassa dan karbon (Uthbah, Sudiana, \& Yani, 2017). Selain itu, faktor lain yang mempengaruhi rendahnya serapan karbon adalah kerapatan tegakan bahwa kerapatan berbanding lurus dengan serapan karbon di hutan kota dalam mereduksi $\mathrm{CO}_{2}$ (Handika, Fitrada, \& Rhodiyah, 2020). Kerapatan tegakan pada areal penanaman di Taman Hutan Kampus IPB Dramaga sangat rendah masing-masing hanya memiliki jarak tanam $1 \mathrm{~m} \times 1 \mathrm{~m}$. Perbedaan biomassa tersebut diakibatkan oleh adanya perbedaan jumlah pohon/kerapatan dan diameter rata-rata pohon (Saharjo, \& Wardhana, 2011).

Taman Kanal Banjir Timur memiliki nilai biomassa, simpanan karbon, dan serapan karbon tertinggi. Hal ini karena pohon-pohon di lokasi tersebut memiliki rata-rata diameter yang besar, kerapatan pohon yang termasuk tinggi, dan jenis pohon yang memiliki berat jenis rata-rata cukup tinggi. Besarnya biomassa pada masing-masing petak ukur akan dipengaruhi oleh jenis pohon, jumlah, dan diameter (Istomo, \& Farida, 2010; Yunita, 2016). Gambaran umur populasi sering dinyatakan dalam diameter, sehingga semakin bertambah umur tanaman, maka semakin besar kandungan biomassa di atas tanah (Manafe, Kaho, \& Risamasu, 2016). Perbedaan cadangan karbon yang tersimpan disebabkan adanya perbedaan besaran diameter diantara tegakan, dimana semakin besar diameter pohon penyusun suatu lahan, maka berat biomassa pohon pada lahan tersebut akan semakin besar pula. Secara umum biomassa pada tiap bagian pohon terbesar diperoleh dari pohon dengan diameter yang terbesar pula (Samsoedin, Sukiman, Wardani, \& Heriyanto, 2016). Berat biomassa yang besar akan mempengaruhi besarnya cadangan karbon pada suatu lahan (Hanafi, \& Bernardianto, 2012). Besarnya stok karbon tiap bagian pohon dipengaruhi oleh biomassa. Oleh karena itu, setiap peningkatan terhadap biomassa akan diikuti oleh peningkatan stok karbon. Hal ini menunjukkan besarnya biomassa berpengaruh terhadap stok karbon. Menurut Heriyanto, Wibowo, \& Garsetiasih (2010) menyatakan bahwa kandungan karbon pada tanaman menggambarkan berapa besar tanaman tersebut mengikat $\mathrm{CO}_{2}$ dari udara. 
Peningkatan diameter disebabkan karena penyimpanan biomassa hasil konversi $\mathrm{CO}_{2}$ yang semakin bertambah besar seiring dengan semakin banyaknya $\mathrm{CO}_{2}$ yang diserap pohon (Manafe, Kaho, \& Risamasu, 2016).

Biomassa pada batang umumnya memiliki kontribusi paling besar dibandingkan dengan biomassa pada bagian lainnya (Putri, \& Wulandari, 2015). Hal ini disebabkan karena batang menyimpan sebagian besar cadangan hasil fotosintetis untuk pertumbuhan tanaman. Sebagian karbon akan menjadi bahan bakar untuk proses hidup tanaman dan sebagian masuk dalam struktur tumbuhan dan menjadi bagian dari tumbuhan, misalnya selulosa (Garsetiasih, Rianti, \& Heriyanto, 2018). Selulosa merupakan molekul gula linear berantai panjang yang tersusun oleh karbon, sehingga semakin tinggi selulosa, maka kandungan karbon akan semakin tinggi. Makin besar diameter pohon diduga memiliki potensi selulosa dan zat penyusun kayu lainnya akan lebih besar.

Tegakan di Taman Kanal Banjir Timur umumnya sudah berupa pohon, dan memiliki tajuk yang tebal. Daun sendiri merupakan bagian dari tanaman atau pohon yang memiliki kontribusi dalam menghasilkan biomassa. Hal ini karena daun merupakan tempat berlangsungnya proses fotosintesis, sehingga berpengaruh terhadap ukuran biomassa. Meskipun proses fotosintesis menyerap karbon dioksida, namun hasil fotosintesis tersebut didistribusikan ke bagian lainnya (batang, cabang, dan ranting), sehingga kandungan biomassa pada bagian non-fotosintesis akan lebih besar dibandingkan dengan bagian daun yang melakukan proses fotosintesis (Widyasari, Saharjo, Solichin, \& Istomo, 2010).

Tingginya potensi simpanan karbon dipengaruhi juga oleh berat jenis vegetasinya (Mohammadi, Limaei, Lohmander, \& Olsson, 2017). Jumlah karbon tersimpan berbeda-beda tergantung pada jenis tumbuhan, karena berat jenisnya berbeda (Pebriandi, Sribudiani, \&
Mukhamadun, 2013). Hasil penelitian menunjukkan bahwa semakin tinggi berat jenis, maka kandungan biomassa karbon yang tersimpan pada tumbuhan tersebut semakin besar. Hal ini diperkuat sejalan dengan pendapat Tim Perubahan Iklim Badan Litbang Kehutanan (TPIBLK, 2010), yang menyatakan bahwa besarnya biomassa ditentukan oleh diameter setinggi dada, tinggi total pohon, berat jenis, dan kesuburan tanah. Tipe hutan yang memiliki komposisi berat jenis pohon tinggi mempunyai potensi simpanan yang cenderung lebih tinggi daripada tipe hutan dengan kerapatan tinggi tetapi jenis pohonnya berberat jenis rendah (Maulana, 2010). Peningkatan dimensi pohon melalui diameter dan tinggi pohon akan meningkatkan jumlah simpanan karbonnya (Basrudin, \& Wahyuni, 2017).

\section{KESIMPULAN DAN SARAN}

\section{A. Kesimpulan}

Potensi biomassa tersimpan di Taman Hutan Kanal Banjir Timur dengan luas areal 3,94 ha adalah 580,277 ton dengan serapan karbon dioksida $\left(\mathrm{CO}_{2}\right)$ sebesar 1.000,01 ton. Potensi biomassa tersimpan di Taman Hutan United Tractors Head Office dengan luas areal 18,8 ha adalah 543,97 ton dengan serapan karbon dioksida $\left(\mathrm{CO}_{2}\right)$ sebesar 937,53 ton. Potensi biomassa tersimpan di Taman Wisata Mangrove Muara Tawar Bekasi dengan luas areal 0,20 ha adalah 25,17 ton dengan serapan karbon dioksida $\left(\mathrm{CO}_{2}\right)$ sebesar 46,10 ton. Potensi biomassa tersimpan di Taman Hutan Bukit Golf Pantai Indah Kapuk dengan luas areal 0,18 ha adalah 80,68 ton dengan serapan karbon dioksida $\left(\mathrm{CO}_{2}\right)$ sebesar 147,91 ton. Potensi biomassa tersimpan di Taman Hutan Kampus IPB Dramaga Bogor dengan luas areal 0,09 ha adalah 0,09 ton dengan serapan karbon dioksida $\left(\mathrm{CO}_{2}\right)$ sebesar 0,16 ton. 


\section{B. Saran}

Berdasarkan hasil analisis pendugaan kandungan karbon di beberapa tempat studi di wilayah Jakarta dan Bogor menunjukkan bahwa hutan kota memiliki peran penting dalam menyerap karbon. Oleh karena itu, untuk mendukung informasi dan data potensi serapan karbon tersebut, maka perlu dilakukan pemantauan berkelanjutan setiap tahun, sehingga dapat diketahui kecenderungan potensi daya serap karbon tersebut secara berkala meski berada pada lokasi dan luasan yang sama.

\section{UCAPAN TERIMA KASIH}

Kami sangat berterimakasih kepada $P T$ United Tractors Tbk yang telah memberikan kepercayaan untuk melakukan kajian ini. Hasil kajian ini diharapkan dapat menjadi parameter pengelolaan wilayah perkotaan yang berkelanjutan untuk mengurangi emisi.

\section{DAFTAR PUSTAKA}

Azzahra, F.S., Suryanti, S., \& Febrianto, S. (2020). Estimasi serapan karbon pada hutan mangrove Desa Bedono, Demak, Jawa Tengah. Journal of Fisheries and Marine Research, 4(2), $308-315$.

Azizah, M., Yuliani, M., \& Heriyanto. (2019). Cadangan karbon pada tegakan pohon hutan kota di Taman Margasatwa Ragunan DKI Jakarta. Florea 6(1), 1-9.

Banjarnahor, K.G., Setiawan, A., \& Darmawan, A. (2018). Estimasi perubahan karbon tersimpan di atas tanah di Arboretum Universitas Lampung. Jurnal Sylva Lestari, 6(2), 51-59.

Basrudin, \& Wahyuni, S. (2017). Keragaman dan potensi biomassa tumbuhan bawah pada Kecamatan Laeya Kabupaten Konawe Selatan. Jurnal Ecogreen, 3(2), 97-104.
Brown, S. (1997). Estimating biomass and biomass change of tropical forests: a Primer. FAO Forestry Paper, 134, 1333.

Chave, J., Andalo, C., Brown, S., Cairns, M., A., Chambers, J., Q., Eamus, D., Fölster, H., Fromard, F., Higuchi, N., Kira, T., Lescure, J.P., Nelson, B., W., Ogawa, H., Puig, H., Riéra, B., \& Yamakura, T. (2005). Tree allometry and improved estimation of carbon stocks and balance in tropical forests. Oecologia, 145(1), 87-99. https://doi.org/10.1007/s00442-0050100-x.

Darmanto, N.S., \& Sofyan, A. (2012). Analisis distribusi pencemar udara $\mathrm{NO} 2, \mathrm{SO} 2, \mathrm{CO}$ dan $\mathrm{O} 2$ di Jakarta dengan WRF-CHEM. Jurnal Teknik Lingkungan, 18(1), 54-64.

Dharmawan, I.W.S. (2010). Pendugaan karbon di atas tanah pada tegakan Rhizophora mucronata di Ciasem, Purwakarta. Jurnal Ilmu Pertanian Indonesia, 15(1), 50 -56.

Garsetiasih, R., Rianti, A., \& Heriyanto, N. M. (2018). Potensi tumbuhan bawah pada tegakan hutan tanaman Acacia. Jurnal Penelitian Hutan Tanaman, 15(2), 97-111.

Hamdaningsih, S.S., Fandeli., \& Baiquni, M. (2010). Studi kebutuhan hutan kota berdasarkan kemampuan vegetasi dalam penyerapan karbon di Kota Mataram. Majalah Geografi Indonesia, 24(1), 1-9. https://jurnal.ugm.ac.id/mgi/article/do wnload/13336/9553.

Hanafi, N., \& Bernardianto, R.B. (2012). Pendugaan cadangan karbon pada sistem penggunaan lahan di areal PT. Sikatan Wana Raya. Media Sains, 4(2).

Handika, R.A., Fitrirada, W., \& Rodhiyah, Z. (2020). Potensi vegetasi hutan kota dalam reduksi emisi karbon dioksida $\left(\mathrm{CO}_{2}\right)$ di Kota Jambi. Biospecies, 13(1), 23-28. https://doi.org/10.22437/biospecies.v 13 i1.8463. 
Heriyanto, N.M., Wibowo, A., \& Garsetiasih, R. (2010). Potensi karbon pada hutan tanaman tusam, mahoni dan jati di Jawa Barat dan Banten. Jurnal Penelitian Hutan Tanaman, 7(3), 1-11.

Ismiyati, Marlita, D., \& Saidah, D. (2014). Pencemaran udara akibat emisi gas buang kendaraan bermotor. Jurnal Manajemen Transportasi \& Logistik, 1(3), 241-248.

Istomo, I., \& Farida, N.E. (2017). Potensi simpanan karbon di atas permukaan tanah tegakan Acacia nilotica $\mathrm{L}$. (Willd) ex. Del. di Taman Nasional Baluran, Jawa Timur. Jurnal Pengelolaan Sumberdaya Alam dan Lingkungan (Journal of Natural Resources and Environmental Management), 7(2), 155-162. https://doi.org/10.29244/jpsl.7.2.155162

Izzah, A. N., Nasrullah, N., \& Sulistyantara, B. (2019). Efektifitas jalur hijau jalan dalam mengurangi polutan gas $\mathrm{CO}$. Jurnal Ilmu Pertanian Indonesia, 24(4), 337-342.

Karim, M.A., Purwiyanto, A.I.S., \& Agustriani, F. (2019). Analysis of carbon content $(C)$ production rate of mangrove litter at Pulau Payung, Banyuasin District. Marine Science Research Journal 11(1), 1-8.

Manafe, G., Kaho, M. R., \& Risamasu, F. (2016). Estimasi biomassa permukaan dan stok karbon pada tegakan pohon Avicennia marina dan Rhizophora mucronata di Perarian Pesisir Oebelo Kabupaten Kupang. Bumi Lestari Journal of Environment, 16(2), 163. https://doi.org/10.24843/blje.2016.v1 6.i02.p09

Maulana, I.S. (2010). Pendugaan pensitas karbon tegakan hutan alam di Kabupaten Jayapura, Papua. Jurnal Penelitian Sosial dan Ekonomi Kehutanan, 7(4), 261-274. https://doi.org/10.20886/jsek.2010.7.4 .261-274
Mohammadi, Z., Limaei, S.M., Lohmander, P., \& Olsson, L. (2017). Estimating the aboveground carbon sequestration and its economic value (case study: Iranian caspian forests). Journal of Forest Science, 63(11), 511-518. https://doi.org/10.17221/88/2017-JFS

Noor, Y.R., Khazali, M., \& Suryadiputra, I.N.N. (2006). Panduan pengenalan mangrove di Indonesia. PHKA/WI-IP, Bogor.

Pebriandi, Sribudiani, E, \& Mukhamadun. (2013). Estimation of the carbon potential in the above ground at the stand level poles and trees in Sentajo Protected Forest. http://jom.unri.ac.id/index.php/ JOMFAPERTA/article/viewFile/2670 12602

Putri, A.H.M., \& Wulandari, C. (2015). Potensi penyerapan karbon pada tegakan damar mata kucing (Shorea Javanica) di Pekon Gunung Kemala Krui Lampung Barat. Jurnal Sylva Lestari, 3(2), 13. https://doi.org/10.23960/js12313-20

Saharjo, B.H., \& Wardhana, H.F.P. (2011). Pendugaan potensi simpanan karbon pada tegakan pinus (Pinus merkusii) di KPH. Cianjur Perum Perhutani Unit III Jawa Barat dan Banten. Jurnal Penelitian Silvikultur Tropika 3(1), 96-100.

Samsoedin, I., Sukiman, H., Wardani, M., \& Heriyanto, N.M. (2016). Biomassa dan kandungan karbon kayu afrika (Maesopsis emenii Engl.) di Bodogol, Sukabumi, Jawa Barat. Jurnal Penelitian Hutan Tanaman, 13(1), 7381.

https://doi.org/10.20886/jpht.2016.13. 1.73-81.

Sedjarawan, W., Akhbar, \& Arianingsih, I. (2014). Biomassa dan karbon pohon di atas permukaan tanah di tepi jalan Taman Nasional Lore Lindu. Jurnal Warta Rimba, 2(1), 105-111.

TPIBLK [Tim Perubahan Iklim Badan Litbang Kehutanan]. (2010). Cadangan karbon pada berbagai tipe 
Nyoto Santoso, Sutopo, Gilang Prastya Pambudi, Vregat Febriansyah Danarta, Rohma Alif Wibisono, Tri Puji Astuti dan/and Dimas Aryo Wicaksono

hutan dan jenis tanaman di Indonesia. Pusat Penelitian dan Pengembangan Perubahan Iklim dan Kebijakan. Kementrian Kehutanan, Bogor. IDN.

Uthbah, Z., Sudiana, E., \& Yani, E. (2017). Analisis biomassa dan cadangan karbon pada berbegai umur tegakan damar (Agathis dammara (Lamb.) Rich.) di KPH Banyumas Timur. Scripta Biologica, 4(2), 119. https://doi.org/10.20884/1.sb.2017.4.2 .404

Warpur, M. (2016). Struktur vegetasi hutan mangrove dan pemanfaatannya di Kampung Ababiaidi Distrik Supiori Selatan Kabupaten Supiori. Jurnal Biodjati, 1(1), 19-26.

Widyasari, E.N.A., Saharjo, B.H., Solichin., \& Istomo. (2010). Pendugaan biomassa dan potensi karbon terikat di atas permukaan tanah pada hutan rawa gambut bekas terbakar di Sumatera Selatan. Jurnal Ilmu Pertanian Indonesia, 15(1), 41-49.

Yunita L. 2016. Pendugaan cadangan karbon tegakan Meranti (Shorea Leprosula) di hutan alam pada area silin PT Inhutani II Pulau Laut Kalimantan Selatan. Jurnal Hutan Tropis. 4(2), 187-197.

Yustiningsih, M. (2019). Intensitas cahaya dan efisiensi fotosintesis pada tanaman naungan dan tanaman terpapar langsung cahaya matahari. Jurnal Pendidikan Biologi, 4(2), 4449. 